\title{
STUDIES OF BERRY DRYING PROCESS IN INFRARED FILM DRYER
}

\author{
Aivars Aboltins, Janis Palabinskis, Kaspars Vartukapteinis \\ Latvia University of Agriculture \\ aivars.aboltins@inbox.lv, Janis.palabinskis@1lu.lv, kaspars.vartukapteinis@1lu.lv
}

\begin{abstract}
The research work analyzed the two fresh berries (strawberry and pumpkin samples) drying process in the infrared film dryer. Infrared drying takes place at low temperatures (up to $40^{\circ} \mathrm{C}$ ) and it helps keep the maximum product quality and natural colour. The product moisture removal depends on the location of the products in IR dryer (distance from the infrared source - film) and product location at the air inlet and outlet. Strawberries drying experimental data show that the most rapid moisture removal is observed in the samples on the top and bottom shelf, which is about $15-20 \%$ higher than in the samples on the middle shelf. Moisture removal from pumpkin samples on the middle shelf is approx. $30 \%$ slower than from the samples on the upper and lower shelf. This could be explained by the IR direct impact on the samples placed on the top and bottom shelves. Using the experimental data and multivariate analysis it has been found that the product moisture removal depends on its placement (distance from the heating film and the air inlet, outlet) and the drying time.
\end{abstract}

Keywords: IR drying, strawberry, pumpkin.

\section{Introduction}

Infrared drying (IR) is an effective method of dehydration. It is based on the fact that infrared radiation of certain wavelengths is actively absorbed by water contained in the product. The wave energy directly affects the water of the product. The absorptivity, the depth of material and the transmissivity are dependent on the IR wave length, density and the properties of the irradiated material. Nowadays, consumers appreciate the quality of the dried product, the texture, colour, nutritional content etc. Drying temperature $40-60^{\circ} \mathrm{C}$ is optimal to preserve vitamins, biologically active substances, natural colour and aroma of the dried products.

The number of published articles related to infrared food drying is increasing every year. A general review of food drying using infrared heating has been published [1]. As it is noted, there is a need for more studies concerning infrared drying. There should be researches with different products with different infrared drying conditions.

Strawberries is a very popular fruit as they have good taste and nutritional value. Strawberries are very susceptible to microbiological deterioration, it is very difficult to commercialise them. Temperature and relative humidity of ambient air affect on the appearance and quality of fresh strawberry. These berries have very short postharvest life.

There are different researches on strawberry drying. There are researches on strawberry drying in solar dryers. The total phenolic and anthocyanin content of strawberries after sample drying in direct and indirect solar dryers was determined [2]. The different types (half, quarter, slices) of strawberries drying curves, quality attributes were investigated in the indirect forced convection solar dryer [3]. The influence of the heating shelf temperature on physical properties of freeze-dried strawberries was investigated in [4]. Application of a heating shelf temperature of $30^{\circ} \mathrm{C}$ results in obtaining the highest water vapour sorption rate [4]. The halogen drying of strawberry slices in drying temperatures 60,70 and $80^{\circ} \mathrm{C}$ was studied in [5]. Drying time and drying rate of quarters of strawberries at drying temperatures 60,70 and $80^{\circ} \mathrm{C}$ with the infrared dryer were examined [6].

Pumpkin is a seasonal crop and fresh pumpkins are very sensitive to microbial spoilage. Pumpkin is a good source of carotene, water-soluble vitamins and amino acids. Pumpkins have an important health protection effect. Due to its nature, pumpkin requires more effective preservation methods. Drying is one of the oldest methods of food preservation. There are a lot of researches on pumpkin drying thematic [7-9]. The pumpkin drying kinetics and influence of convective drying in chemical properties was shown [7]. The drying temperature effect on physico-chemical properties on pumpkin powder was evaluated [8]. The results show that drying temperature changes the colour and decreases the carotenoid content. The drying kinetics of samples with different drying temperatures, sample thickness and air velocities were studied [9]. Using thin layer models and multi-layer feed - forward artificial neural network method kinetic models were developed here. 
The fruit (apple, banana slices and grape halves) drying process investigation in the infrared film dryer at low temperatures is shown [10]. This does not take into account the distance from the IR source.

The presented paper examines the strawberry and pumpkin sample drying process in the IR film dryer with small heating up to $40^{\circ} \mathrm{C}$. As shown in [1] the distance between the IR emitters and drying material influences the drying time, energy consumption and quality of the final dried product. There are investigated and compared two product (strawberry slices and pumpkin samples) drying dynamics depending on the distance from the IR source (film) and the distance from the inlet and outlet of air in the dryer.

\section{Materials and methods}

The experiment was made at the Grain Drying and Storage Scientific Laboratory at the Latvia University of Agriculture.

The infrared (IR) dryer (Fig. 1) consisted of a drying chamber $(80 \times 55 \times 75 \mathrm{~cm})$ with a heat source IR film (South Korea EXCEL). The drying equipment body from the inside from all sides was insulated with foam rubber and aluminium foil. It increases the drying efficiency by reducing heat losses to the environment. The infrared film with a thickness of $0.338 \mathrm{~mm}$ was located on the aluminium foil along the perimeter of the drying chamber. The applied film power was $150 \mathrm{~W} \cdot \mathrm{m}^{-2}$. The maximum temperature on the surface of the film reaches $45^{\circ} \mathrm{C}$.

The drying chamber shelf system can accommodate up to eight fibre glass sieve shelves with wooden frames, depending on the amount of the drying material (Fig. 2). Shelving is adjustable relative to the upper and lower heating elements and is interconnected with the screw nut. The screw nut adjustment allows for easy shelf height change through various studies. The studies were conducted with three shelf systems and the first plate was located $15 \mathrm{~cm}$ from the lower heating element, the second $-40 \mathrm{~cm}$ and the third $-65 \mathrm{~cm}$ or $10 \mathrm{~cm}$ from the upper heater (Fig. 1).

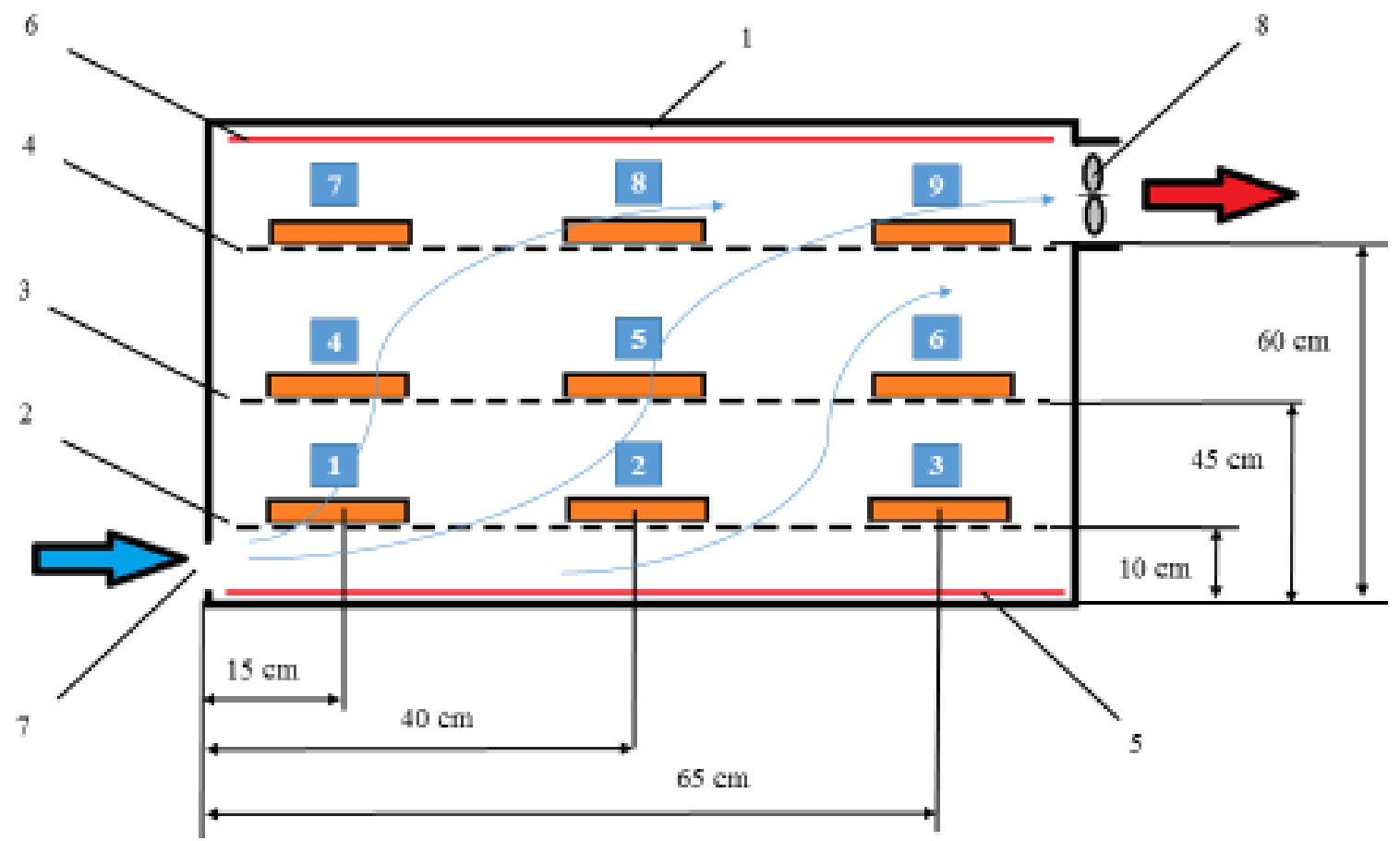

Fig. 1. Schematic view of IR dryer: 1 - dryer body; 2-4 - shelves; 5,6 - IR drying film; 7 - air inlet holes; 8 - fan

Air supply is held by eight adjustable variable cross-section holes that are below the shelf level. The experiments were performed with the fan with a total maximum capacity of $100 \mathrm{~m}^{3} \cdot \mathrm{h}^{-1}$ and power $19 \mathrm{~W}$, which is placed on the top of the side wall of the equipment (Fig. 1 and Fig. 2).

The pumpkins were cut into $1 \times 1 \times 2 \mathrm{~cm}$ thick samples (Fig. 3), strawberries were cut into $1 \mathrm{~cm}$ thick slices. The samples were placed on round (diameter $20 \mathrm{~cm}$ ) aluminium drying bowls, which 
consisted of a fine mesh screen Fig. 3-5. Strawberries in the bowl are placed on paper. These sample bowls were put on the drying chamber shelves. The bowls were placed $10 \mathrm{~cm}, 35 \mathrm{~cm}$ and $60 \mathrm{~cm}$ from the IR film on the bottom and 15, 40 and $65 \mathrm{~cm}$ from the air inlet (Fig. 1).

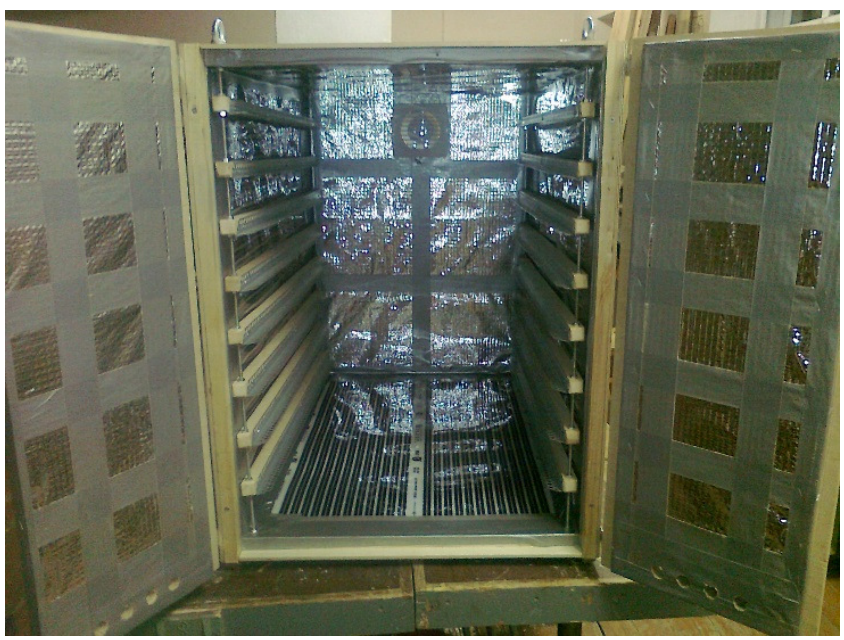

Fig. 2. IR dryer shelving system

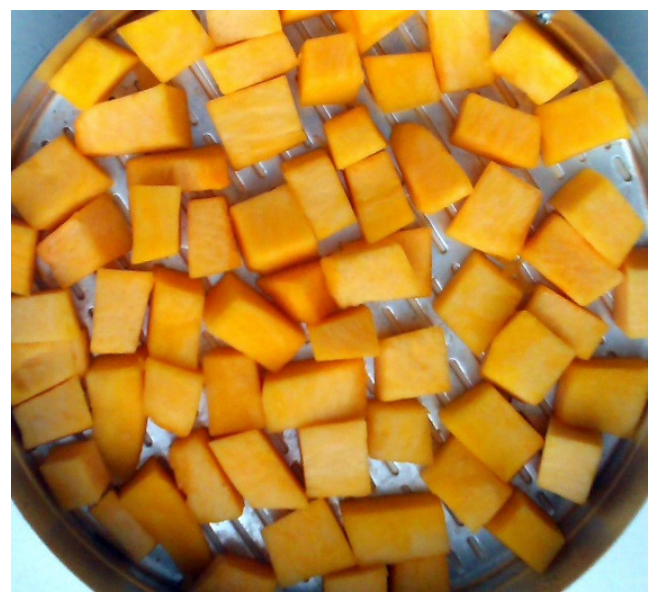

Fig. 3. Bowl with fresh pumpkin samples

The moisture content in the material was measured by gravimetric measurement in time intervals. The pumpkin and strawberry samples were weighed on the digital laboratory balance KERN-440-35N with maximum load weight $400 \mathrm{~g}$ and with resolution $0.01 \mathrm{~g}$. The total drying time was 6 and 7 hours. The samples were regularly weighed during the experiment and the values were recorded regularly to determine the mass changes depending on the drying time at certain temperature. The initial moisture content of strawberries was $91.5 \%$ and pumpkin samples $90.5 \%$. The dried strawberry and pumpkin samples are shown in Fig. 4 and Fig. 5.

The dry matter is determined by laboratory equipment Memmert drying the product at $103{ }^{\circ} \mathrm{C}$ to constant weight of the product. The average inlet air temperature during the experiment was $20 \pm 0.5^{\circ} \mathrm{C}$ with average humidity $49.3 \%$.

The experimental data were processed with the program packets MathCad (multivariable nonlinear analysis) and MatLab (contour plot).

\section{Results and discussion}

Our interest was to find out the pumpkin and strawberry drying efficiency dependence on the position in the dryer. We studied two cases: berry sample moisture dependence on the drying time and the distance from the inlet holes at different height from the drying film and material moisture dependence on the drying time and the distance from the IR film at different distance from the inlet holes.

Using the experimental data nonlinear multivariable equations between the material moisture $M(t, x)$, drying time $\mathrm{t}$ and the distance from the inlet holes at various shelf heights were obtained.

For pumpkin samples as follows.

Distance from the IR film on the bottom $10 \mathrm{~cm}$ :

$$
M(t, x)=91.3-0.047 \cdot t-2.09 \cdot 10^{-5} \cdot t^{2}-0.042 \cdot x+4.93 \cdot 10^{-4} \cdot x^{2}-2.83 \cdot 10^{-4} \cdot t \cdot x .
$$

Distance from the IR film on the bottom $60 \mathrm{~cm}$ :

$$
M(t, x)=91.1-0.04 \cdot t-3.39 \cdot 10^{-5} \cdot t^{2}-0.031 \cdot x+5.16 \cdot 10^{-4} \cdot x^{2}-1.11 \cdot 10^{-3} \cdot t \cdot x .
$$

For strawberry slices as follows.

Distance from the IR film on the bottom $10 \mathrm{~cm}$ :

$$
M(t, x)=99-0.116 \cdot t+2.6 \cdot 10^{-5} \cdot t^{2}-0.613 \cdot x+8.22 \cdot 10^{-3} \cdot x^{2}-3.63 \cdot 10^{-4} \cdot t \cdot x .
$$

Distance from the IR film on the bottom $35 \mathrm{~cm}$ : 


$$
M(t, x)=85-0.176 \cdot t+9.03 \cdot 10^{-5} \cdot t^{2}+0.532 \cdot x-7.15 \cdot 10^{-3} \cdot x^{2}+1.06 \cdot 10^{-4} \cdot t \cdot x .
$$

Distance from the IR film on the bottom $60 \mathrm{~cm}$ :

$$
M(t, x)=86.4-0.085 \cdot t-9.94 \cdot 10^{-5} \cdot t^{2}+0.48 \cdot x-4.915 \cdot 10^{-3} \cdot x^{2}-1.377 \cdot 10^{-3} \cdot t \cdot x,
$$

where $M(t, x)$ - material moisture, $\%$;

$t$ - drying time, min;

$x$ - distance from the air inlet, $\mathrm{cm}$.

The coefficient of determination in these cases was more that $R^{2}=0.96$.

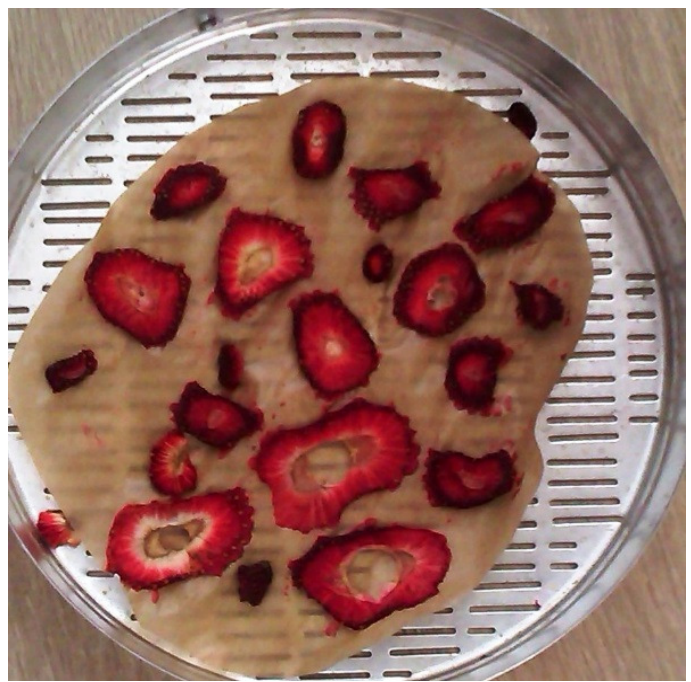

Fig. 4. Bowl with dried strawberry samples

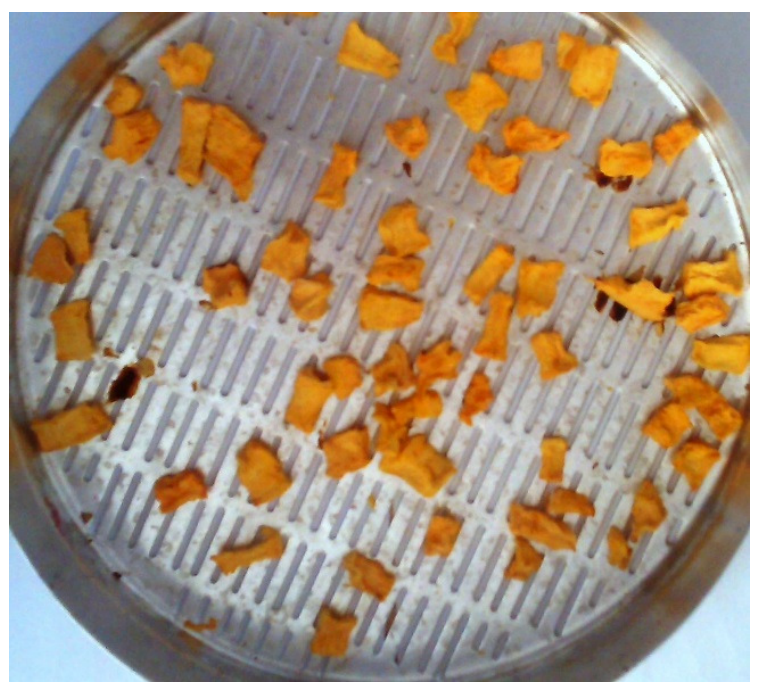

Fig. 5. Bowl with dried pumpkin samples

Graphically we compare the strawberry and pumpkin sample moisture removal dynamics in the case when the products are placed on the top shelf (equations (2) and (5)) Fig. 6. and Fig. 7.

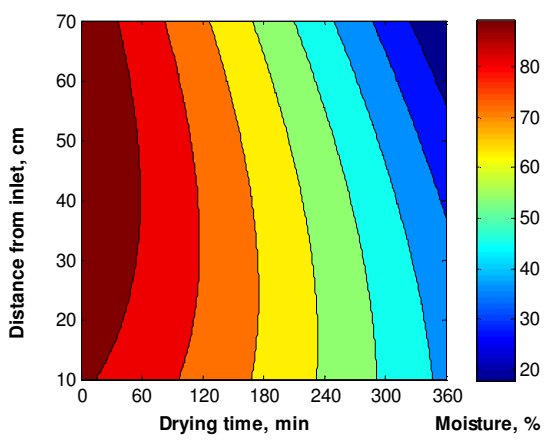

Fig. 6. Drying time and distance from air inlet influence on strawberry drying dynamics on top shelf

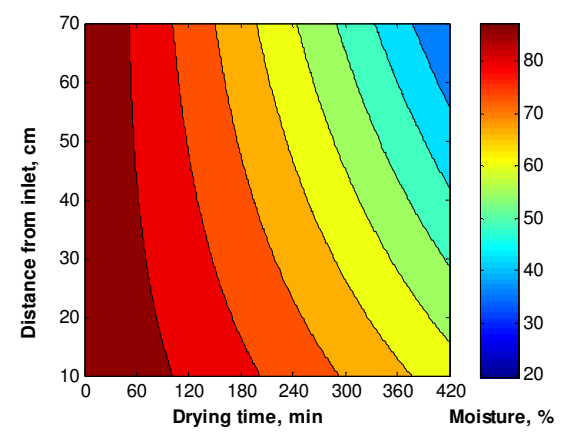

Fig. 7. Drying time and distance from air inlet influence on pumpkin drying dynamics on top shelf

The experimental data show that the outlet air temperature was on average 12 degrees higher than the inlet air temperature during the experiment. Temperature between the lower and upper shelf was 6$7{ }^{\circ} \mathrm{C}$ on average. The experimental results show that the strawberry slices under given conditions dry much faster than pumpkin samples. The contour form difference could be explained by the difference of the samples; strawberries were placed on paper impervious to the air flow. An important role is played by a fan;the closer the air outlet, the faster drying.

The distance from the IR film also affects moisture removal from the material. The effects of three different locations $(15,40,65 \mathrm{~cm}$ from the air inlet) depending on the distance from the IR film on the bottom were tested. It should be noted that the IR film was on the bottom and top $(75 \mathrm{~cm}$ from the bottom) in the dryer. 
For pumpkin samples as follows.

Distance from the air inlet $15 \mathrm{~cm}$ :

$$
M(t, y)=89.3-0.042 \cdot t-3.21 \cdot 10^{-5} \cdot t^{2}+0.105 \cdot y-1.41 \cdot 10^{-3} \cdot y^{2}-2.2 \cdot 10^{-4} \cdot t \cdot y .
$$

Distance from the air inlet $40 \mathrm{~cm}$ :

$$
M(t, y)=85.2-0.042 \cdot t-2.9 \cdot 10^{-5} \cdot t^{2}+0.462 \cdot y-6.45 \cdot 10^{-3} \cdot y^{2}-6.17 \cdot 10^{-4} \cdot t \cdot y .
$$

Distance from the air inlet $65 \mathrm{~cm}$ :

$$
M(t, y)=92-0.06 \cdot t-0.8 \cdot 10^{-5} \cdot t^{2}-0.093 \cdot y+1.45 \cdot 10^{-3} \cdot y^{2}-1.03 \cdot 10^{-3} \cdot t \cdot y .
$$

For strawberry slices as follows.

Distance from the air inlet $15 \mathrm{~cm}$

$$
M(t, y)=96-0.104 \cdot t+1.31 \cdot 10^{-5} \cdot t^{2}-0.573 \cdot y+9.71 \cdot 10^{-3} \cdot y^{2}-9.48 \cdot 10^{-4} \cdot t \cdot y
$$

Distance from the air inlet $40 \mathrm{~cm}$

$$
M(t, y)=87.5-0.138 \cdot t+1.707 \cdot 10^{-6} \cdot t^{2}+0.366 \cdot y-5.04 \cdot 10^{-3} \cdot y^{2}-2.57 \cdot 10^{-4} \cdot t \cdot y
$$

Distance from the air inlet $65 \mathrm{~cm}$

$$
M(t, y)=89.4-0.114 \cdot t+1.374 \cdot 10^{-4} \cdot t^{2}+0.177 \cdot y-1.84 \cdot 10^{-3} \cdot y^{2}-2.23 \cdot 10^{-3} \cdot t \cdot y
$$

where $M(t, y)$ - material moisture, \%;

$y$ - distance from the IR film on the bottom, $\mathrm{cm}$.

Graphic comparison of the obtained equations (8) and (11) is shown in Fig. 8. and Fig. 9.

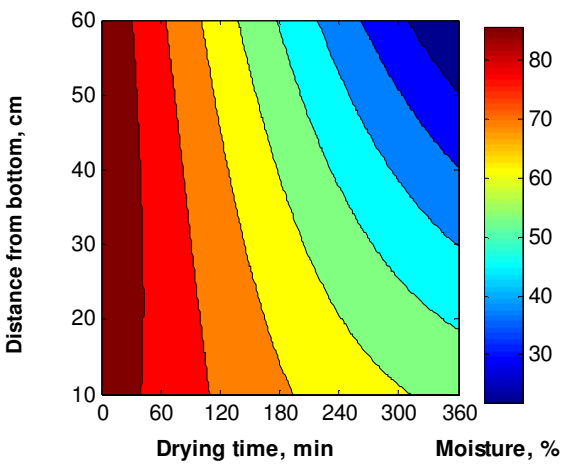

Fig. 8. Drying time and distance (from IR dryer bottom) influence on water removal from strawberries $65 \mathrm{~cm}$ from air inlet

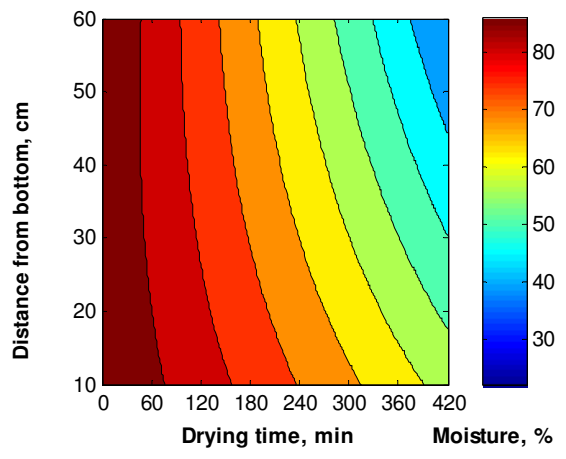

Fig. 9. Drying time and distance (from IR dryer bottom) influence on water removal from pumpkins $65 \mathrm{~cm}$ from air inlet

The strawberry drying experimental data show that the most rapid moisture removal is observed in the samples on the top and bottom shelf, which is about 15-20\% higher than in the samples on the middle shelf. It should be noted that higher moisture runoff occurs in the drying chamber close to the air inlet and outlet locations.

A similar situation was seen in the pumpkin sample drying. Moisture removal from the samples on the middle shelf is approx. $30 \%$ slower than from the samples on the upper and lower shelf. This could be explained by the IR direct impact on the samples placed on the top and bottom shelves.

The upper IR film had greater effect on moisture removal. It could be explained by aluminium basis of the trays. For strawberries this effect was much more Fig.8. It could be explained by paper effect laid on aluminium mesh. For IR rays it is harder to warm the product.

\section{Conclusions}

The study shows that drying using the IR film is well used at low temperatures (up to $40^{\circ} \mathrm{C}$ ) and it helps maintain the maximum product quality and natural colour. 
The strawberries drying experimental data show that the most rapid moisture removal is observed in the samples on the top and bottom shelf, which is about 15-20\% higher than in the samples on the middle shelf. It should be noted that higher moisture runoff occurs in the drying chamber close to the air inlet and outlet locations.

Moisture removal from pumpkin samples on the middle shelf is approx. $30 \%$ slower than from the samples on the upper and lower shelf. This could be explained by the IR direct impact on the samples placed on the top and bottom shelves.

The experimental results show that strawberry slices under given conditions dry much faster than pumpkin samples.

\section{References}

1. Riadh M., Ahmad S., Marhaban M., Soh A. Infrared heating in food drying: an overview, Drying technology, Vol. 33, 2015, pp. 322-335

2. Lopez-Vidana E., Pilatowsky I., Navarr0-Ocana A., Drying of strawberry in a direct and indirect solar dryer (Effects of drying methods on total phenolic content), IJAAEE, Vol.2, (2) 2015, pp 61-63.

3. El-Beltagy A., Gamea G., Amer Essa A. Solar drying characteristics of strawberry J. of Food Engineering , vol. 78 (2), 2007, pp.456-464

4. Ciurzynska A., Lenart A., The influence of temperature on rehydration and sorption properties of freeze-dried strawberries, Crot. J. Food Sci.Tehnol, Vol.1 (1), 2009, pp. 15-23

5. Al-Hilphy A., Al-RikabiA., Mathematical modelling and experimental study on thin layer halogen dryer of strawberry and study its effect on antioxidant activity, AJABS, Vol.8 (4) 2013, pp. 268281

6. Ertekin C., Gozlekci S., Heybeli N., Gencer A., Adak N., Oksal S. Drying of starwberries with infrared dryer, Proceedings International Conference of Agricultural Engineering, Zurich, 0610.07.2014 - www.eurageng.eu

7. Guine R., Pinho S., Barroca M. Study of convective drying of pumpkin (Cucurbia maxima)Food and bioproducts processing, vol 89, 2011, pp. 422-428.

8. Roongruangsri W., Bronlund E. Effect of air-drying temperature on physico-chemical, powder properties and sorption characteristics of pumpkin powders, International food research journal vol 23 (3), 2016, pp. 962-972

9. Onwude D., Hashim N., Janius B., Nawi N., Abdam K. Modeling the convective drying process of pumpkin (Cucurbita moshata) using an artificial neural network, International food research journal vol 23 (Suppl), 2016, pp. 237-243

10. Aboltins A., Palabinskis J. Fruit drying process investigation in infrared film dryer. Agronomy research, Vol.14(1), 2016, pp. 5-13. 